Received Date : 06-Oct-2015

Revised Date : 09-Jun-2016

Accepted Date : 02-Oct-2016

Article type : Case Report

\title{
Durable remission of both multicentric Castleman's disease and Kaposi's sarcoma with valganciclovir, rituximab and liposomal doxorubicin in an HHV8
} positive, HIV-negative patient.

\section{Corresponding Author}

Dr Geoff Chong

Olivia Newton-John Cancer Wellness \& Research Centre

Studley Rd Heidelberg

Victoria, Australia 3084

email geoff.chong@onjcri.org.au

fax $\quad+61394576698$

phone +61394965000

Co-Authors: Murphy $\mathrm{C}^{1}$, Hawkes $\mathrm{E}^{1}$, Chionh $\mathrm{F}^{1,2}$, Chong $\mathrm{G}^{1}$.

1. Department of Medical Oncology, Austin Health, Heidelberg, Australia

This is the author manuscript accepted for publication and has undergone full peer review but has not been through the copyediting, typesetting, pagination and proofreading process, which may lead to differences between this version and the Version of Record. Please cite this article as doi: $10.1111 /$ jcpt.12472

This article is protected by copyright. All rights reserved 
2. Olivia Newton-John Cancer Research Institute and School of Cancer Medicine, La Trobe University, Melbourne, Victoria, Australia

Key words: HHV-8, Multi-centric Castleman's Disease, Kaposi Sarcoma, valganciclovir, rituximab

Conflicts of Interest: The authors have no conflicts of interest to declare.

Word Count: 1570

\section{SUMMARY}

What is known and objective

Human herpes virus 8 (HHV-8) positive, HIV-negative multicentric Castleman's disease is a rare lymphoproliferative disorder with no standardised treatment. Concurrent Kaposi sarcoma, another HHV-8 related disease, is uncommon in HIV-negative patients. The role of antiviral therapy and rituximab in HIV-negative patients is not well established.

\section{Case Description}

We report a case of a five year, durable remission of HHV-8 positive, HIV-negative comorbid multicentric Castleman's disease and Kaposi sarcoma treated with long-term valganciclovir, following initial rituximab and liposomal doxorubicin.

\section{What is new and conclusion}

Currently there is no defined role for anti-viral therapy in the treatment of HIV-negative HHV-8 positive multicentric Castleman's disease and Kaposi sarcoma. Ganciclovir followed by indefinite, continuous valganciclovir is thought to have contributed significantly to the durable response in this case.

This article is protected by copyright. All rights reserved 


\section{WHAT IS KNOWN AND OBJECTIVE}

Human herpes virus 8 (HHV-8) is an oncogenic virus involved in the pathogenesis of Kaposi sarcoma, primary effusion lymphoma and multicentric Castleman's disease. Multicentric Castleman's disease is a rare systemic lymphoproliferative disorder that most commonly occurs in patients infected with human immunodeficiency virus (HIV). Almost all cases of HIV-positive multicentric Castleman's disease are co-infected with HHV-8. ${ }^{1}$ This is in contrast to HIV-negative multicentric Castleman's disease, where HHV-8 co-infection occurs in only 7 - $50 \%$ of cases. ${ }^{2}$ A concurrent diagnosis of Kaposi sarcoma has been reported in less than $13 \%$ of HIV negative multicentric Castleman's disease. ${ }^{3}$ Due to the rarity of this disease, large prospective trial data are lacking. Chemotherapy and, more recently, targeted therapy with anti-CD20 and anti-IL-6 monoclonal antibodies have demonstrated efficacy. ${ }^{4-7}$ The role of anti-viral drugs in the management of HHV-8-positive, HIV-negative multicentric Castleman's disease and Kaposi sarcoma has not been established. We present a case of HHV-8 positive, HIV-negative multicentric Castleman's disease with concurrent Kaposi sarcoma in whom the combination of antiviral therapy with ganciclovir and valganciclovir and treatment with the anti-CD20 monoclonal antibody rituximab resulted in long-term control of HHV-8 viraemia and consequently long term remission of both diseases.

\section{CASE DESCRIPTION}

A previously well 62 year old man of Mediterranean descent presented with fevers, sweats, fatigue and anaemia. Examination and imaging revealed widespread lymphadenopathy, splenomegaly and Kaposi sarcoma involving all four limbs. Intranodal Kaposi sarcoma with associated plasma cell variant multicentric Castleman's disease was confirmed on inguinal node biopsy. HIV serology was negative. Quantitative real-time polymerase chain reaction revealed HHV-8 DNA in pooled plasma and lymphocytes (cycle threshold $\left(C_{t}\right) 32.5$ ). The $C_{t}$ for positive controls included in each HHV-8 PCR assay were all within $2 C_{t}$ of their standard values (VIDRL, Australia). Lower $C_{t}$ values reflect higher viral load. The virus is deemed undetectable at $C_{t}>45$ (Figure 1).

The patient received prednisolone $60 \mathrm{mg}$ daily for one week prior to commencing 6 cycles of liposomal doxorubicin (Table 1). The prednisolone was weaned over the course of chemotherapy. Treatment resulted in clinical improvement and radiological response. 
Less than two months after completing chemotherapy the patient relapsed with biopsy confirmed recurrence of multicentric Castleman's disease. Two cycles of cyclophosphamide, etoposide, prednisolone and vincristine (Table 1) were administered with documented partial radiological response. Cycle two was complicated by a life-threatening pneumonia which did not respond to broad spectrum antibiotics and required both inotropic and noninvasive ventilator support. No bacterial pathogen was identified on blood or sputum cultures however HHV-8 viraemia $\left(C_{t} \quad 25\right)$ was noted. Intravenous ganciclovir was commenced with clinical improvement and reduction in HHV-8 viral levels $\left(C_{t} 28\right)$. Ganciclovir was replaced with valganciclovir 900mg oral twice daily. After three weeks the patient recovered and HHV-8 was undetectable, therefore valganciclovir was ceased.

Within seventeen days of ceasing valganciclovir multicentric Castleman's diseaserecurred along with re-emergence of HHV-8 viraemia $\left(C_{t} 35\right)$ and a new Kaposi sarcoma lesion. Intravenous ganciclovir was recommenced, resulting in resolution of symptoms and regression of the lesion and lymphadenopathy but ongoing low-level viraemia $\left(C_{t} 34-38\right)$. The patient was discharged on continuous oral valganciclovir $900 \mathrm{mg}$ daily.

A confirmed relapse of multicentric Castleman's disease occurred three months after this admission, at which time, notably, HHV8 was still detectable $\left(C_{t} 38\right)$. The multicentric Castleman's disease was successfully controlled with 4 doses of weekly rituximab (Table 1). Kaposi sarcoma progressed shortly after completion of rituximab. A rechallenge with 6 cycles of liposomal doxorubicin (Table 1) achieved a documented near-complete clinical response.

Another biopsy-confirmed relapse of multicentric Castleman's disease and an associated rise in HHV-8 levels $\left(C_{t} 30\right)$, occurred eleven months after completion of rituximab therapy and six months following cessation of liposomal doxorubicin. One cycle of cyclophosphamide, vincristine and prednisolone (Table 1) was administered but due to thrombocytopenia, chemotherapy was replaced with four doses of single-agent weekly rituximab (Table 1). Valganciclovir was continued throughout treatment. Near-complete clinical and radiological response in multicentric Castleman's disease were achieved and there was a reduction in HHV-8 levels, although these were still detectable. 
Low-level HHV-8 viraemia $\left(C_{t} 30-38\right)$ persisted and another flare of Kaposi sarcoma followed this second course of rituximab. This required retreatment with a further six cycles of liposomal doxorubicin (Table 1) and during this time HHV-8 viraemia resolved. Valganciclovir $900 \mathrm{mg}$ oral daily has continued and HHV-8 levels have remained undetectable. With more than five years of follow up from completion of chemotherapy no further treatment has been required for either multicentric Castleman's disease or Kaposi sarcoma.

In summary, this man had multiple and frequent relapses of both multicentric Castleman's disease and Kaposi sarcoma early in the disease course, all of which occurred in the presence of detectable HHV-8 viraemia. Introduction of life-long valganciclovir reduced HHV-8 viral load to an undetectable level over a period of almost 18 months. Subsequently, HHV-8 levels remained undetectable and no further relapses have occurred with more than 5 years follow up.

Several chemotherapy regimens have been evaluated in multicentric Castleman's disease and, with few exceptions, yielded poor outcomes. ${ }^{8}$ Liposomal doxorubicin or paclitaxel induce response in Kaposi sarcoma but, in most cases, duration of response is limited. ${ }^{9-11}$ In the twenty years since HHV-8 was first identified there have been significant advances in our understanding of its role in the oncogenesis of multicentric Castleman's disease leading to the implementation of new treatment strategies for this disease. ${ }^{12}$ The HHV- 8 infected cells in multicentric Castleman's disease are large CD20+ plasmablasts. ${ }^{13}$ Depletion of these cells by the anti-CD20 antibody rituximab, and subsequent restoration of anti-viral T-cell immunity may contribute to the efficacy of these agents. ${ }^{2}$ In prospective trials of HIVpositive multicentric Castleman's disease, rituximab improved constitutional symptoms and produced objective responses in up to $70 \%$ of patients. ${ }^{6,14}$ Improvement in overall survival has also been demonstrated, albeit in a retrospective study. ${ }^{15}$ As a result rituximab has become a standard component of first-line treatment for HIV-positive multicentric Castleman's disease. ${ }^{7}$ In HIV-negative diseasedata are scarce, with few reports describing remissions following rituximab. ${ }^{2,16,17}$ 
In HIV-positive patients diagnosed with dual multicentric Castleman's disease and Kaposi sarcoma the use of rituximab to treat multicentric Castleman's disease is associated with disease progression of Kaposi sarcoma in up to $50 \%$ of patients. ${ }^{7}$ In this population Kaposi sarcoma progression can be managed with the addition of liposomal doxorubicin to rituximab therapy. ${ }^{5}$ The phenomenon of rituximab-related Kaposi sarcoma flare was noted in this case and has been described in one other case of HIV-negative HHV-8-positive multicentric Castleman's disease. ${ }^{16}$ Whilst in our patient the Kaposi sarcoma was successfully controlled with liposomal doxorubicin and anti-viral treatment, the outcome of the Kaposi sarcoma flare in Law et al's case has not been reported.

There is evidence in HIV-positive multicentric Castleman's disease and Kaposi sarcoma that HHV-8 levels can be used to monitor and predict relapse. ${ }^{18}$ In this population, cidofovir, foscarnet and ganciclovir have all been associated with a reduction in the development of Kaposi sarcoma ${ }^{19}$ and ganciclovir and foscarnet with a decrease in HHV-8 viraemia. ${ }^{20-22}$ In HIV-negative patients the relationship between HHV-8 viral load and these diseases, particularly multicentric Castleman's disease, remains unclear. HHV-8 viraemia is a common finding in multicentric Castleman's disease recurrence, ${ }^{23}$ and there is some data suggesting a relationship between reduced HHV- 8 viral load and disease response. ${ }^{17}$ Broad-spectrum anti-viral agents directed against HHV-8 are not part of the routine management of multicentric Castleman's disease or Kaposi sarcomadue to lack of proven benefit. Only a few reports of this treatment approach exist, mostly in HIV-positive patients, however even responses considered durable are reported as lasting only 3-18 months. ${ }^{24-26}$ In all of these cases anti-viral treatment was ceased upon resolution of multicentric Castleman's disease recurrence, except for one case where continuation was not explicitly stated.

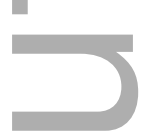

In our case HHV-8 viraemia was associated with severe systemic symptoms and progression of both multicentric Castleman's disease and Kaposi sarcoma followed by clinical and biochemical response to antiviral treatment. Ongoing suppression of HHV-8 altered the disease course of both conditions. Prior to the use of antiviral suppression our patient experienced rapid symptomatic recurrences punctuated by responses to chemotherapy 
which were not durable. In contrast the two relapses of multicentric Castleman's diseaseand Kaposi sarcoma during the first year of antiviral therapy achieved remissions of relatively long duration. Of note, these occurred in the context of an initial interruption to valganciclovir and declining but persistent HHV-8 viraemia. Whilst rituximab induced responses in multicentric Castleman's disease during this period, it was associated with progression of Kaposi sarcoma in both instances necessitating treatment with liposomal doxorubicin. Following complete resolution of HHV-8 viraemia, and with ongoing valganciclovir, there has been no recurrence of either disease observed in more than five years of follow up at our institution. Inarguably rituximab contributed to remission of multicentric Castleman's disease in this case but the disease recurred following the first course of treatment in the setting of persistent HHV-8 viraemia. Rituximab has no activity in Kaposi sarcoma, suggesting the addition of valganciclovir to conventional chemotherapy and anti-CD20 targeted treatment in this patient played a role in the long-term control of these diseases.

\section{WHAT IS NEW AND CONCLUSION}

Dual HHV-8 related diseases are rarely seen in HIV-negative patients. To our knowledge this is the first case where a durable remission of both multicentric Castleman's disease and Kaposi sarcoma was achieved with the addition of ongoing antiviral therapy to sequential rituximab and liposomal doxorubicin in an HHV8-positive, HIV-negative patient. Repeated flares of Kaposi sarcoma followed treatment with rituximab, demonstrating this phenomenon is not isolated to HIV-positive patients. We suggest that long-term control of HHV-8 contributed to the treatment of multicentric Castleman's disease and Kaposi sarcoma in this patient with HIV-negative disease and was, in part, responsible for his durable remission.

\section{REFERENCES}

1. Waterston A, Bower M. Fifty years of multicentric Castleman's disease. Acta Oncol. 2004;43:698-704.

This article is protected by copyright. All rights reserved 
2. Nicoli P, Familiari U, Bosa M, et al. HHV8-positive, HIV-negative multicentric Castleman's disease: early and sustained complete remission with rituximab therapy without reactivation of Kaposi sarcoma. Int J Hematol. 2009;90:392-396.

3. Du MQ, Bacon CM, Isaacson PG. Kaposi sarcoma-associated herpesvirus/human herpesvirus 8 and lymphoproliferative disorders. J Clin Pathol. 2007;60:1350-1357.

4. Muzes G, Sipos F, Csomor J, Sreter L. Successful tocilizumab treatment in a patient with human herpesvirus 8-positive and human immunodeficiency virus-negative multicentric Castleman's disease of plasma cell type nonresponsive to rituximab-CVP therapy. APMIS. 2013;121:668-674.

5. Uldrick TS, Polizzotto MN, Aleman $\mathrm{K}$, et al. Rituximab plus liposomal doxorubicin in HIV-infected patients with KSHV-associated multicentric Castleman disease. Blood. 2014;124:3544-3552.

6. Gerard L, Berezne A, Galicier L, et al. Prospective study of rituximab in chemotherapy-dependent human immunodeficiency virus associated multicentric Castleman's disease: ANRS 117 CastlemaB Trial. J Clin Oncol. 2007;25:3350-3356.

7. Bower M, Dalla Pria A. What Is the best treatment for HIV-associated multicentric Castleman disease? Clin Adv Hematol Oncol. 2012;10:207-209.

8. Mylona EE, Baraboutis IG, Lekakis LJ, Georgiou O, Papastamopoulos V, Skoutelis A. Multicentric Castleman's disease in HIV infection: a systematic review of the literature. AIDS Rev. 2008;10:25-35.

9. Gbabe $\mathrm{OF}$, Okwundu $\mathrm{Cl}$, Dedicoat $\mathrm{M}$, Freeman EE. Treatment of severe or progressive Kaposi's sarcoma in HIV-infected adults. Cochrane Database Syst Rev. 2014;8:CD003256.

10. Brambilla L, Romanelli A, Bellinvia $M$, et al. Weekly paclitaxel for advanced aggressive classic Kaposi sarcoma: experience in 17 cases. Br J Dermatol. 2008;158:1339-1344.

11. Di Lorenzo G, Di Trolio R, Montesarchio V, et al. Pegylated liposomal doxorubicin as second-line therapy in the treatment of patients with advanced classic Kaposi sarcoma: a retrospective study. Cancer. 2008;112:1147-1152.

12. Kaplan LD. Human herpesvirus-8: Kaposi sarcoma, multicentric Castleman disease, and primary effusion lymphoma. Hematology Am Soc Hematol Educ Program. 2013;2013:103-108.

This article is protected by copyright. All rights reserved 
13. Laurent $C$, Meggetto $F$, Brousset $P$. Human herpesvirus 8 infections in patients with immunodeficiencies. Hum Pathol. 2008;39:983-993.

14. Bower M, Powles T, Williams $\mathrm{S}$, et al. Brief communication: rituximab in HIVassociated multicentric Castleman disease. Ann Intern Med. 2007;147:836-839.

15. Hoffmann C, Schmid H, Muller M, et al. Improved outcome with rituximab in patients with HIV-associated multicentric Castleman disease. Blood. 2011;118:3499-3503.

16. Law AB, Ryan G, Lade S, Prince HM. Development of Kaposi's sarcoma after complete remission of multicentric Castlemans disease with rituximab therapy in a HHV8positive, HIV-negative patient. Int J Hematol. 2010;91:347-348; author reply 349.

17. Dossier A, Meignin V, Fieschi C, Boutboul D, Oksenhendler E, Galicier L. Human herpesvirus 8-related Castleman disease in the absence of HIV infection. Clin Infect Dis. 2013;56:833-842.

18. Stebbing J, Adams C, Sanitt A, et al. Plasma HHV8 DNA predicts relapse in individuals with HIV-associated multicentric Castleman disease. Blood. 2011;118:271-275.

19. Mazzi R, Parisi SG, Sarmati L, et al. Efficacy of cidofovir on human herpesvirus 8 viraemia and Kaposi's sarcoma progression in two patients with AIDS. AIDS. 2001;15:2061-2062.

20. Martin DF, Kuppermann BD, Wolitz RA, Palestine AG, Li H, Robinson CA. Oral ganciclovir for patients with cytomegalovirus retinitis treated with a ganciclovir implant. Roche Ganciclovir Study Group. N Engl J Med. 1999;340:1063-1070.

21. Robles R, Lugo D, Gee L, Jacobson MA. Effect of antiviral drugs used to treat cytomegalovirus end-organ disease on subsequent course of previously diagnosed Kaposi's sarcoma in patients with AIDS. J Acquir Immune Defic Syndr Hum Retrovirol. 1999;20:34-38.

22. Glesby MJ, Hoover DR, Weng S, et al. Use of antiherpes drugs and the risk of Kaposi's sarcoma: data from the Multicenter AIDS Cohort Study. J Infect Dis. 1996;173:14771480.

23. Grandadam $\mathrm{M}$, Dupin $\mathrm{N}$, Calvez $\mathrm{V}$, et al. Exacerbations of clinical symptoms in human immunodeficiency virus type 1-infected patients with multicentric Castleman's disease are associated with a high increase in Kaposi's sarcoma herpesvirus DNA load in peripheral blood mononuclear cells. J Infect Dis. 1997;175:1198-1201. 
24. Dieval C, Bonnet F, Mauclere S, et al. Multicentric Castleman disease: Use of HHV8 viral load monitoring and positron emission tomography during follow-up. Leuk Lymphoma. 2007;48:1881-1883.

25. Casper C, Nichols WG, Huang ML, Corey L, Wald A. Remission of HHV-8 and HIVassociated multicentric Castleman disease with ganciclovir treatment. Blood. 2004;103:1632-1634.

26. Sbenghe MM, Besa E, Mahipal A, Dulau Florea A, Bray P, Caro J. HHV-8-associated multicentric Castleman's disease in HIV-negative patient: a novel therapy for an orphan disease. Oncologist. 2012;17:145-146; author reply 147-148.

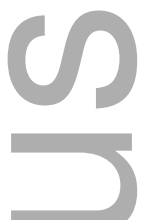

\section{Tables \& Figures}

Table 1. Chemotherapy and targeted therapy regimens

\begin{tabular}{|c|c|c|}
\hline Regimen & Doses & Cycle length \\
\hline Liposomal doxorubicin & liposomal doxorubicin $20 \mathrm{mg} / \mathrm{m} 2$ & 28 days \\
\hline CEOP & $\begin{array}{l}\text { cyclophosphamide } 750 \mathrm{mg} / \mathrm{m}^{2} \\
\text { etoposide } 100 \mathrm{mg} / \mathrm{m}^{2} \\
\text { vincristine } 1.4 \mathrm{mg} / \mathrm{m}^{2} \mathrm{D} 1 \text { (dose capped at } 2 \mathrm{mg} \text { ) } \\
\text { prednisolone } 100 \mathrm{mg} \text { D1-5 }\end{array}$ & 21 days \\
\hline Rituximab & rituximab $375 \mathrm{mg} / \mathrm{m} 2$ & 7 days \\
\hline 담 & $\begin{array}{l}\text { cyclophosphamide } 750 \mathrm{mg} / \mathrm{m}^{2} \mathrm{D} 1 \\
\text { vincristine } 1.4 \mathrm{mg} / \mathrm{m}^{2} \mathrm{D} 1 \text { (dose capped at } 2 \mathrm{mg} \text { ) } \\
\text { prednisolone } 40 \mathrm{mg} / \mathrm{m}^{2} \mathrm{D} 1-5\end{array}$ & 21 days \\
\hline
\end{tabular}

Figure 1. HHV-8 viraemia $\left(C_{t}^{\dagger}\right)$ and disease activity 


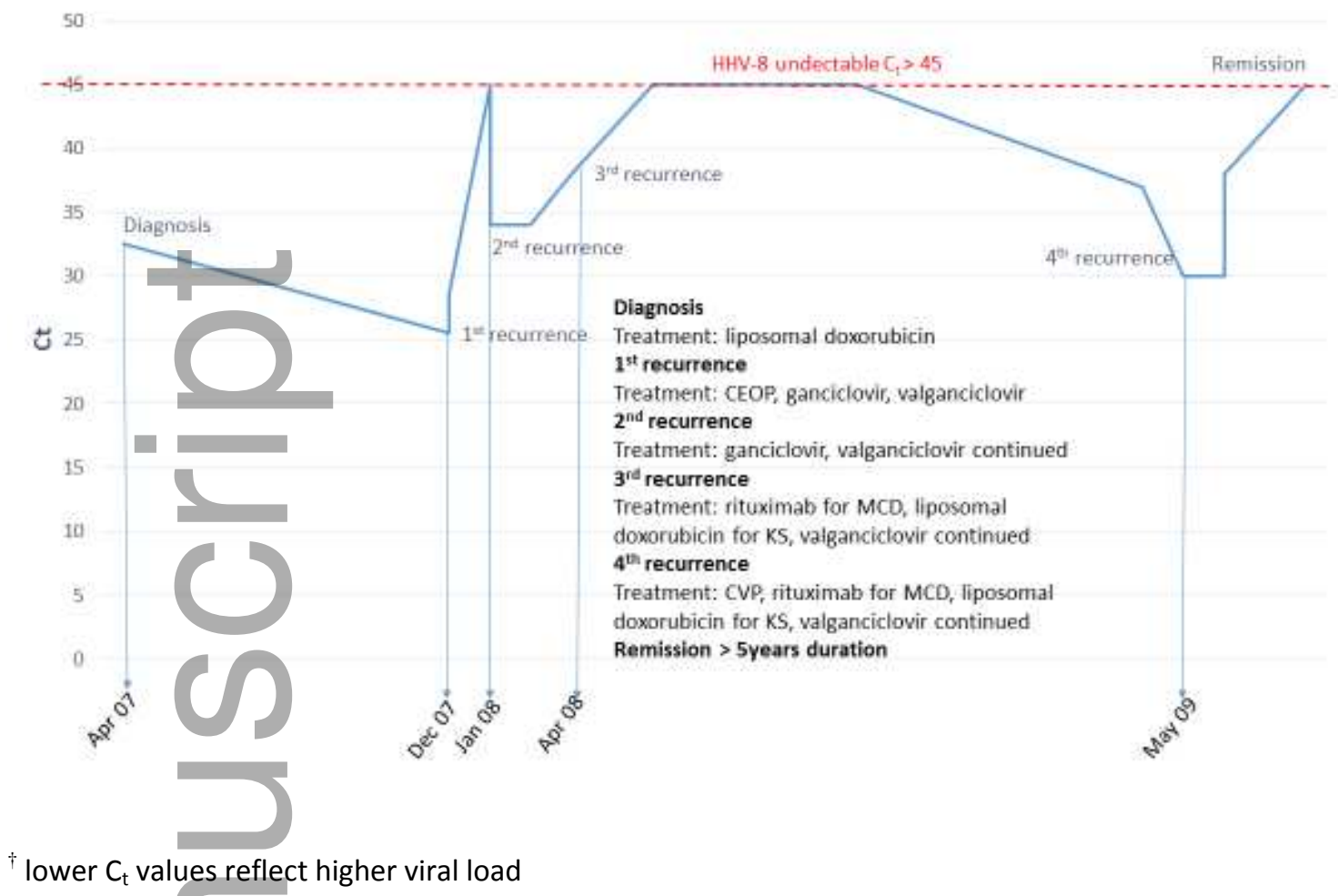

${ }^{\dagger}$ lower $C_{t}$ values reflect higher viral load

Figure 1. Abbreviations: CEOP cyclophosphamide etoposide vincristine prednisolone; CVP cyclophosphamide, vincristine, prednisolone; KS Kaposi sarcoma; MCD multicentric Castleman's disease

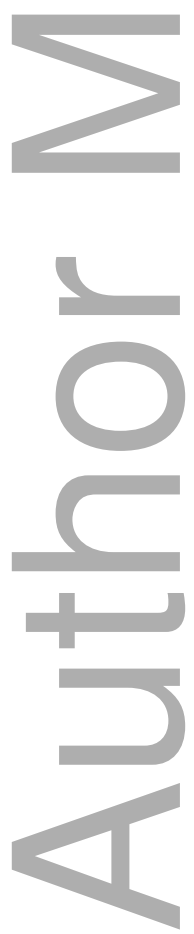




\section{University Library}

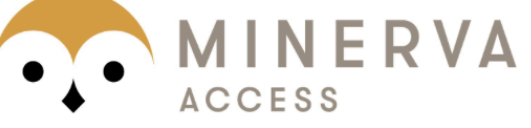

A gateway to Melbourne's research publications

Minerva Access is the Institutional Repository of The University of Melbourne

Author/s:

Murphy, C;Hawkes, E;Chionh, F;Chong, G

Title:

Durable remission of both multicentric Castleman's disease and Kaposi's sarcoma with valganciclovir, rituximab and liposomal doxorubicin in an HHV-8-positive, HIV-negative patient

Date:

2017-02-01

Citation:

Murphy, C., Hawkes, E., Chionh, F. \& Chong, G. (2017). Durable remission of both multicentric Castleman's disease and Kaposi's sarcoma with valganciclovir, rituximab and liposomal doxorubicin in an HHV-8-positive, HIV-negative patient. JOURNAL OF CLINICAL PHARMACY AND THERAPEUTICS, 42 (1), pp.111-114. https://doi.org/10.1111/jcpt. 12472.

Persistent Link:

http://hdl.handle.net/11343/291894 